\title{
A Practical and Efficient Method for the Micropropagation of Japanese Cherry (Prunus sp.)
}

\section{Nguyen Thi Thuy Linh', Pham Thi Ngoc ${ }^{3}$, Ninh Thi Thao ${ }^{1}$ and Nguyen Thi Phuong Thao' ${ }^{2}$}

${ }^{1}$ Faculty of Biotechnology, Vietnam National University of Agriculture, Hanoi 131000 Vietnam

${ }^{2}$ VinEco Agricultural Investment Development and Production Limited Liability Company, Hanoi 131000, Vietnam

${ }^{3}$ Faculty of Biotechnology, Vietnam National University of Agriculture, Hanoi 131000, Vietnam

\begin{abstract}
This study was conducted to establish the procedure for in vitro propagation of Japanese cherry (Prunus sp.) to produce large quantity of plantlets and initial planting materials for climate adaptation research of this plant in Hanoi. Single nodal stems were used as the primary explants and initially produced shoots on MS medium supplemented with $1 \mathrm{mg} \mathrm{L}^{-1}$ BA. The highest shoot multiplication rate (9.57 times) was obtained on MS medium containing $1 \mathrm{mg} \mathrm{L}^{-1} \mathrm{BA}$ and $0.25 \mathrm{mg} \mathrm{L}^{-1} \alpha$-NAA after 8 weeks of culture. $100 \%$ of the shoots produced roots with a mean of 10.10 roots per plant within 4 weeks on $1 / 2$ MSM medium with $4 \mathrm{mg} \mathrm{L}^{-1}$ IBA. The survival rate of in vitro derived plantlets after a 6 to 7 week-period of rooting during acclimatization using a soil: coco peat: smoked rice husks $(2: 2: 1, \mathrm{v} / \mathrm{v} / \mathrm{v})$ substrate was $100 \%$ and acclimatized plantlets showed good growth and development. This is the first report on a practical and efficient in vitro multiplication protocol for Japanese cherry in Vietnam, starting from shoot initiation to establishment of plants under greenhouse conditions.
\end{abstract}

\section{Keywords}

Japanese cherry, micropropagation, Prunus sp.

Received: May 11, 2018

Accepted: July 19, 2018

Correspondence to

nttlinh@vnua.edu.vn

ORCID

Linh Nguyen Thi Thuy

https://orcid.org/0000-0002-3457-

5764

Thao Ninh

https://orcid.org/0000-0002-93120719

\section{Introduction}

Japanese cherry (Prunus sp.) belongs to the Rosaceae family which originated in Asian countries such as Japan, Korea, and China (Hrusa et al., 2002). It is also grown in other countries, such as the United States, Canada, Australia, and Switzerland. Japanese cherry trees feature beautiful canopies and the blossom is known as the national flower of Japan as a symbol of spring, renewal, and hope. Japanese cherry festivals held in many countries such as Japan, 
Korea, the United States, Australia, and Vietnam attract a huge number of tourists from all over the world, bringing tourism revenue for these countries. In Vietnam, Japanese cherry has been grown in small quantities in several provinces, for example, Dalat, Sapa, Mocchau, and Hanoi. However, the flowering of Japanese cherry is only observed in the highland areas. Therefore, to feature blooming Japanese cherry trees at festivals in Hanoi, the organizers have to import Japanese cherry plants right before the festival begins.

Seed germination and cuttings are common methods of propagating Japanese cherry. However, Japanese cherry seeds require a oneto-five-month period of chilling for germination while the survival rate of the cuttings is low because of the difficulty in rooting (Hartman et al., 2010). Micropropagation techniques have been applied in many Prunus species, for example, wild cherry ( $P$. avium) (Ďurkovič, 2006; Mansseri-Lamrioui et al., 2011; Tančeva and Kajba, 2016), apricot (Yildirim et al., 2011), and Chinese plum (Zou, 2010). Micropropagation of $P$. serrulata L. also has been recently investigated by Duta (2008), and Kalinina and Brown (2007). In Vietnam, only one study has been conducted on the micropropagation of Vietnamese peach $(P$. persica) (Anh et al., 2009). The aims of this study were to establish an efficient micropropagation cycle of Japanese cherry in Hanoi for high production of plantlets and provide materials for future research on flowering conditions in Hanoi. This is the first study on the micropropagation of Japanese cherry in Vietnam.

\section{Materials and Methods}

\section{Sterilization and culture initiation}

Japanese cherry (Prunus sp.) collected from Sapa, Laocai were used as the initial materials. Elongated shoots $5-6 \mathrm{~cm}$ in length were cut from the mother plant and the cut ends were dipped in distilled water. Stems without leaves were washed in $1 \%(\mathrm{v} / \mathrm{v})$ detergent solution for 10 min (Sunlight, Unilever, Vietnam) and then rinsed in running tap water. Subsequently, the stems were surface sterilized in $70 \%$ ethanol for
$30 \mathrm{sec}$, followed by immersion in a $0.1 \%(\mathrm{w} / \mathrm{v})$ aqueous mercuric chloride solution for $15 \mathrm{~min}$. Then, stems were cut into $1 \mathrm{~cm}$ single nodal segments after being rinsed 3-4 times with sterile distilled water. Ultimately, single nodal stem explants were placed on solid MS medium (Murashige and Skoog, 1962) supplemented with $1 \mathrm{mg} \mathrm{L}^{-1} \mathrm{BA}$ for shoot regeneration (Yildirim et al., 2011).

\section{Shoot multiplication}

Regenerated shoots $0.8-1.0 \mathrm{~cm}$ in length with 5-7 leaves from the initiation culture were used as explants for shoot multiplication. The shoot explants were placed on solid MS medium (Murashige and Skoog, 1962) supplemented with different concentrations of benzyladenine (BA; 0, 0.5, 1.0, 1.5, and $2.0 \mathrm{mg} \mathrm{L}^{-1}$ ) alone or in combination with $\alpha$-naphthaleneacetic acid $(\alpha$ NAA; $0,0.1$, and $\left.0.25 \mathrm{mg} \mathrm{L}^{-1}\right)$. Data were scored after 8 weeks of culture.

\section{Root induction}

Elongated healthy individual shoots $0.8-1.2$ $\mathrm{cm}$ in length with 6-10 leaves obtained from the previous shoot proliferation experiments were transferred onto different root induction media such as solid MS (Murashige and Skoog, 1962), 1/2 MS (half-strength MS minerals), and 1/2 MSM (half-strength MS minerals with a modified composition of MS vitamins) media supplemented with different concentrations of $\alpha$-NAA $\left(0,0.5,1.0,1.5\right.$, and $\left.2.0 \mathrm{mg} \mathrm{L}^{-1}\right)$ or IBA $\left(0,1.0,2.0,3.0\right.$, and $\left.4.0 \mathrm{mg} \mathrm{L}^{-1}\right)$. The vitamin components of the $1 / 2 \mathrm{MSM}$ medium were $2.0 \mathrm{mg} \mathrm{L}^{-1}$ glycine, $100 \mathrm{mg} \mathrm{L}^{-1}$ myoinositol, $0.5 \mathrm{mg} \mathrm{L}^{-1}$ nicotinic acid, $0.5 \mathrm{mg} \mathrm{L}^{-1}$ pyridoxine, $1.0 \mathrm{mg} \mathrm{L}^{-1}$ thiamin- $\mathrm{HCl}$, and $2.0 \mathrm{mg}$ $\mathrm{L}^{-1}$ ascorbic acid (Kalinina and Brown, 2007). Data were scored after 4 weeks of culture.

\section{Culture media and culture conditions}

All solid media consisted of $0.7 \%(\mathrm{w} / \mathrm{v})$ agar and $3 \%(\mathrm{w} / \mathrm{v})$ sucrose; $\mathrm{pH}$ was adjusted to 5.8 by $1 \mathrm{~N} \mathrm{KOH}$ before being autoclaved at $121^{\circ} \mathrm{C}$ and at $1.1 \mathrm{~atm}$ for $20 \mathrm{~min}$. The cultures were grown in a culture room at $25 \pm 2^{\circ} \mathrm{C}$ under a 16 h-photoperiod in cool white fluorescent light (2000-2500 lux). 


\section{Acclimatization}

5-7-week-old in vitro derived plantlets were taken out of the culture vessels and thoroughly washed to remove the adhering agar. The plantlets were transplanted into plastic pots $(17 \times 19 \mathrm{~cm})$ containing different mixtures of substrates depending on the experiment and kept in the greenhouse for 4 weeks ( 2 plantlets for each pot). All plant pots were kept under shade cloth to avoid direct sunlight and watered twice a day.

Each experiment was performed in triplicate with 10 samples per treatment per replicate.

\section{Statistical analysis}

Analysis of variance (ANOVA) was performed using IRRISTAT 4.0 and means were compared using LSD at a 0.05 level of probability.

\section{Results and Discussion}

\section{Shoot multiplication}

\section{Effects of BA on shoot proliferation}

In this experiment, supplementation with BA showed positive effects on shoot proliferation from shoot explants of Japanese cherry (Table 1, Figure 1). While shoot explants died on the medium without BA supplementation, the presence of $\mathrm{BA}$ in the culture media promoted shoot growth and proliferation. The optimum multiplication rate (7.50 times) was observed on MS medium supplemented with $0.5 \mathrm{mg} \mathrm{L}^{-1}$ BA. However, the multiplication rate significantly decreased with increased concentrations of BA in the culture media (Table 1).

The positive effects of BA on shoot proliferation has been reported in Prunus species. MS medium supplemented with $0.5 \mathrm{mg} \mathrm{L}^{-1} \mathrm{BA}$ was the optimum medium for shoot multiplication of a hybrid of Prunus avium $\times$ Prunus cerasus (Mahdavian et al., 2011), with the multiplication rate of 5.37. The authors also indicated that an increase in the concentration of BA up to $1.0 \mathrm{mg} \mathrm{L}^{-1} \mathrm{BA}$ resulted in significant reductions of the multiplication rate. On the other hand, Kalinina and Brown (2007) fortified MS medium with $1.0 \mathrm{mg} \mathrm{L} \mathrm{L}^{-1} \mathrm{BA}$ for shoot proliferation of nine ornamental cultivars and a fruit cultivar. The ornamental species were $P$. americana, $P$. tomentosa, $P$. cerasifera $\times$. pumila, $P$. glandulosa, $P$. sargentii, $P$. serrulata, $P$. laurocerasus, $P$. triloba, and $P$. virginiana and the fruit cultivar was $P$. persica 'GF305'. Among the cultivars, $P$. glandulosa showed the highest shoot proliferation rate (5.37 times) while the shoot multiplication rate of $P$. serrulata Kwanzan was only 1.72 times. Yildirim et al. (2011) also determined that $1.0 \mathrm{mg} \mathrm{L}^{-1} \mathrm{BA}$ was the most suitable dose for shoot multiplication from shoot explants of $P$. armeniaca, which produced $3.36 \pm 0.24$ shoots per explant. These results indicate that different species might require different concentrations of $\mathrm{BA}$ for the optimum proliferation of auxiliary shoots.

No sign of growth was observed when explants were cultured on media without BA. This result is in agreement with other reports of Durkovič (2006), Mansseri-Lamrioui et al. (2011), and Yildirim et al. (2011). Besides BA, these authors also used other types of cytokinins to promote shoot multiplication of Prunus species. However, shoot proliferation was only obtained in the media supplemented with cytokinin. These results support that a cytokinin is essential for the in vitro culture of Prunus species.

Table 1. Effects of BA concentration on shoot multiplication from shoot explants of Japanese cherry

\begin{tabular}{ccccc}
\hline $\begin{array}{c}\text { BA concentration } \\
\left(\mathrm{mg} \mathrm{L}^{-1}\right)\end{array}$ & $\begin{array}{c}\text { Multiplication rate } \\
\text { (times) }\end{array}$ & $\begin{array}{c}\text { Mean length of shoots } \\
(\mathrm{cm})\end{array}$ & Mean no. of leaves & Shoot properties \\
\hline 0 & - & - & - & - \\
0.5 & 7.50 & 0.78 & 7.44 & ++ \\
1.0 & 5.69 & 0.93 & 7.86 & ++ \\
1.5 & 5.00 & 0.94 & 7.09 & + \\
2.0 & 4.52 & 0.95 & 6.85 & + \\
LSD $_{0.05}$ & 0.47 & 0.45 & 0.56 & \\
CV\% $^{2}$ & 0.6 & 3.5 & 0.5 & \\
\hline
\end{tabular}

Note: -: shoots died, no data; +: small and green shoots; ++: healthy and green shoots with big stems. 


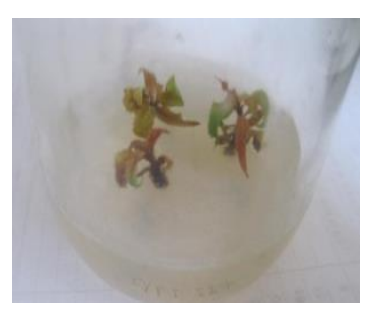

A

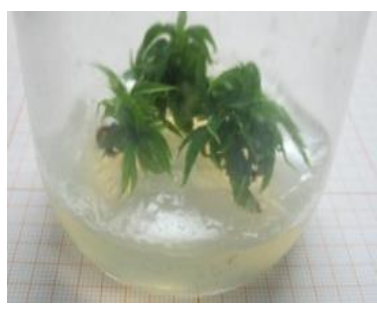

C

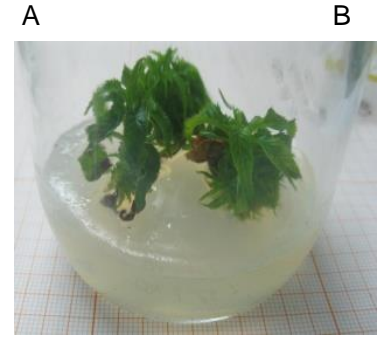

D

B
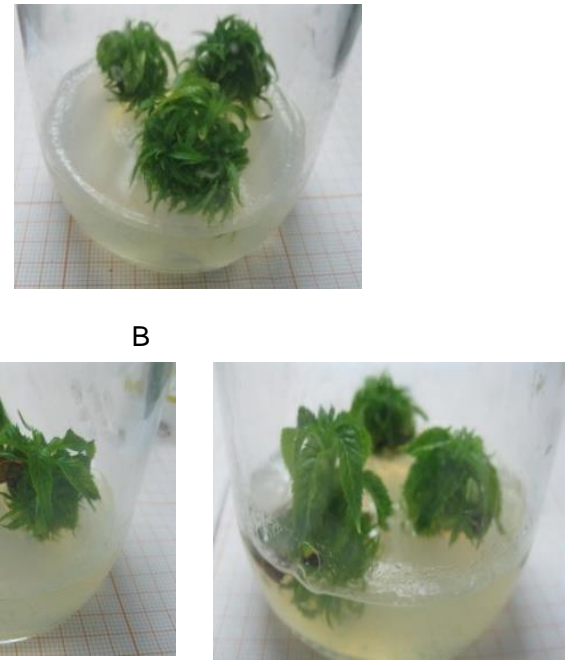

E

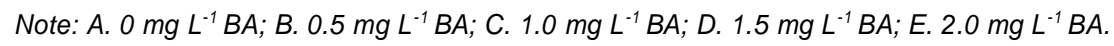

Figure 1. Effects of BA concentration on shoot multiplication from shoot explants of Japanese cherry after 8 weeks of culture

Effects of the combination of BA and $\alpha$-NAA on shoot proliferation

A higher concentration of $\mathrm{BA}$ along with a lower concentration of $\alpha$-NAA has been shown to have a synergistic effect on shoot bud induction in different plants (Fatima and Anis, 2012; Faisal et al., 2018) including Prunus species (Hasan et al., 2010). One of the advantages of supplementing the culture media with a low level of auxin is to negate the effects of the higher cytokinin level on the elongation of axillary shoots (Fatima et al., 2011).

This experiment was performed to investigate combinations of BA and $\alpha-\mathrm{NAA}$ on the coefficient of shoot multiplication of Japanese cherry. The results indicated that shoot multiplication was significantly influenced by the combination of BA and $\alpha$-NAA (Table 2). The medium containing $1.0 \mathrm{mg} \mathrm{L}^{-1} \mathrm{BA}$ and 0.25 $\mathrm{mg} \mathrm{L}^{-1} \alpha$-NAA was found to be optimal for the

Table 2. Effects of BA on shoot multiplication from shoot explants of Japanese cherry

\begin{tabular}{|c|c|c|c|c|c|}
\hline $\begin{array}{c}\text { BA } \\
\text { concentration } \\
\left(\mathrm{mg} \mathrm{L}^{-1}\right)\end{array}$ & $\begin{array}{l}\text { a-NAA concentration } \\
\left(\mathrm{mg} \mathrm{L}^{-1}\right)\end{array}$ & $\begin{array}{l}\text { Multiplication rate } \\
\text { (times) }\end{array}$ & $\begin{array}{l}\text { Mean length of shoots } \\
(\mathrm{cm})\end{array}$ & Mean no. of leaves & $\begin{array}{c}\text { Shoot } \\
\text { properties }\end{array}$ \\
\hline 0 & 0 & - & - & - & - \\
\hline 0.5 & & 4.69 & 0.92 & 6.65 & + \\
\hline 1.0 & 0.10 & 8.47 & 0.85 & 6.96 & ++ \\
\hline 1.5 & & 8.73 & 0.74 & 6.75 & ++ \\
\hline 2.0 & & 6.97 & 0.73 & 6.93 & ++ \\
\hline 0.5 & & 8.13 & 0.82 & 7.51 & ++ \\
\hline 1.0 & 0.25 & 9.57 & 0.83 & 7.98 & ++ \\
\hline 1.5 & & 7.87 & 0.97 & 8.19 & ++ \\
\hline 2.0 & & 7.60 & 0.95 & 7.38 & ++ \\
\hline $\operatorname{LSD}_{0.05}$ & & 0.75 & 0.62 & 0.62 & \\
\hline CV\% & & 0.60 & 4.20 & 0.50 & \\
\hline
\end{tabular}

Note: -: shoots died, no data; +: small and green shoots; ++: healthy and green shoots with big stems. 
shoot multiplication coefficient (9.57). This result is about 1.3 times higher than the result obtained from the best BA treatment in the previous experiment (medium containing 0.5 $\mathrm{mg} \mathrm{L}^{-1} \mathrm{BA}$ only). There were no statistically significant differences in terms of mean length of shoots and mean number of leaves between the optimal treatment $\left(1.0 \mathrm{mg} \mathrm{L}^{-1} \mathrm{BA}\right.$ and 0.25 $\left.\mathrm{mg} \mathrm{L}^{-1} \alpha-\mathrm{NAA}\right)$ and others.

\section{Effects of IBA and basal medium on rooting of in vitro shoots}

Effects of the interactions between the IBA and MS minerals on root formation in vitro of Japanese cherry shoots are shown in Table 3. Supplementing MS or $1 / 2$ MS media with IBA increased the rooting rate and the number of roots on average, while no rooting was obtained on the medium without IBA. The rooting percentage varied from 6.67 to $36.67 \%$ and from 16.67 to $70.00 \%$ on MS or $1 / 2$ MS basal medium fortified with IBA, respectively. 1/2 MS medium supplemented with $4.0 \mathrm{mg} \mathrm{L}^{-1} \mathrm{IBA}$ was the optimal medium for rooting of Japanese cherry and resulted in a $70 \%$ rooting percentage and 5.41 roots per sample on average. These results suggested that the positive effects on root formation were not only caused by the presence of IBA but also by the reduction of the MS mineral concentration.

The positive effects of IBA on rooting in this study are consistent with previous reports on Prunus species, such as $P$. avinum (Mansseri-Lamrioui et al., 2011) and $P$. armeniaca (Yildirim et al., 2011). Similar to this study, no rooting was observed in these species in the absence of auxin. However, the optimum IBA concentrations for rooting of $P$. avinum and $P$ armeniaca were only 1.0 and 2.0 $\mathrm{mg} \mathrm{L}^{-1}$ respectively, which are lower than the optimum concentration of the current study.

The superiority of half strength MS medium for root induction has been reported for Prunus species. According to Fotopoulos and Sotiropoulos (2005), the rooting percentage and mean number of roots per shoot of PR 204/84 rootstock ( $P$. persica $\mathrm{x} P$. amygdalus) was increased by reducing the strength of the MS minerals to half when the IBA concentration was 2.5-10.0 $\mu \mathrm{M}$. Similar effects of halfstrength MS medium were also obtained in almond (P. dulcis) (Choudhary et al., 2015). The favorable effects on rooting by diluting the MS mineral concentration is most likely related to the processes regulating hormonal balance (Amzallag et al., 1992).

Kalinina and Brown (2007) who studied ten Prunus species indicated that $1 / 2$ MS medium with modified concentrations of vitamins and fortified with $3.0 \mathrm{mg} \mathrm{L}^{-1} \mathrm{IBA}$ resulted in a $67-100 \%$ rooting rate. The rooting percentage of four out of the ten species was $100 \%$. Based on the results of Kalinina and Brown (2007) as well as our results, a further experiment was

Table 3. Effects of IBA on rooting in vitro of shoots of Japanese cherry

\begin{tabular}{lcccc}
\hline Basal media & $\begin{array}{c}\text { IBA concentration } \\
\left(\mathrm{mg} \mathrm{L}^{-1}\right)\end{array}$ & Rooting rate (\%) & Mean no. of roots & $\begin{array}{c}\text { Mean length of roots } \\
(\mathrm{cm})\end{array}$ \\
\hline MS & 0 & - & - & - \\
& 1 & 6.67 & 3.00 & 3.60 \\
& 2 & 10.00 & 3.33 & 3.37 \\
& 3 & 20.00 & 3.33 & 3.70 \\
$1 / 2 \mathrm{MS}$ & 3 & 36.67 & 6.55 & 2.21 \\
& 0 & - & - & - \\
& 1 & 16.67 & 1.08 & 2.50 \\
& 2 & 20.00 & 2.87 & 0.55 \\
& 3 & 50.00 & 3.60 & 0.83 \\
\hline
\end{tabular}

Note: -: shoots died, no data available. 
Table 4. Effects of MS strength and IBA on rooting of Japanese cherry shoots in vitro

\begin{tabular}{lcccc}
\hline Basal media & IBA concentration $\left(\mathrm{mg} \mathrm{L}^{-1}\right)$ & Rooting rate $(\%)$ & Mean no. of roots & Mean length of roots $(\mathrm{cm})$ \\
\hline $1 / 2 \mathrm{MS}$ & 3.0 & 50.00 & 3.60 & 0.83 \\
& 4.0 & 70.00 & 5.41 & 0.86 \\
$1 / 2 \mathrm{MSM}$ & 3.0 & 63.49 & 4.49 & 2.68 \\
& 4.0 & 100.00 & 10.10 & 5.39 \\
$\mathrm{LSD}_{0.05}$ & & & 0.14 & 0.68 \\
$\mathrm{CV} \%$ & & & 1.3 & 1.5 \\
\hline
\end{tabular}
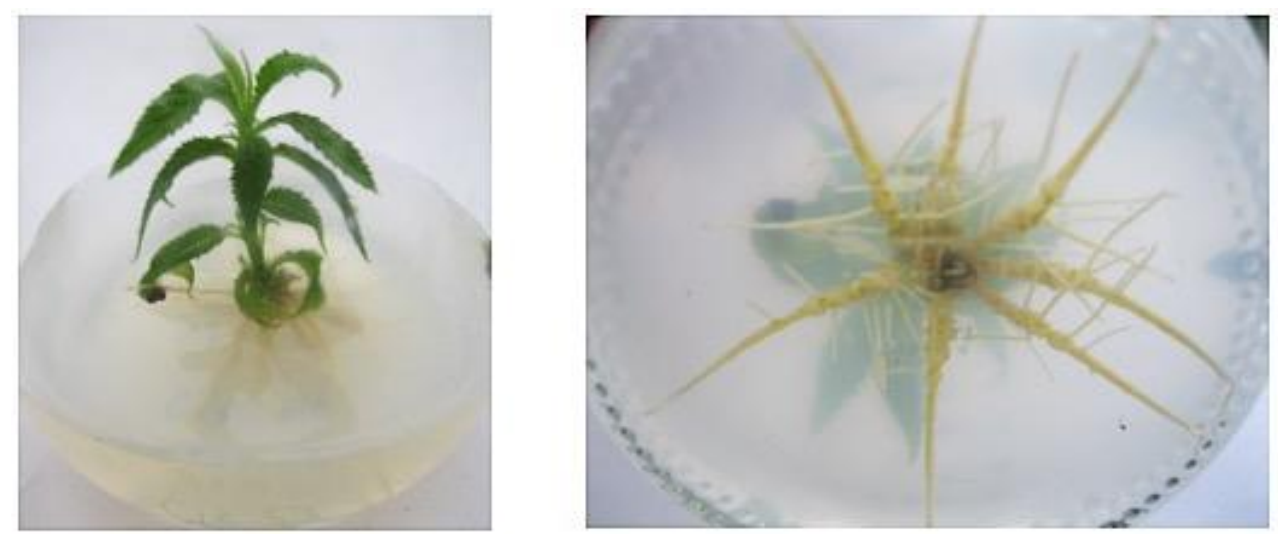

Figure 2. Root formation on 1/2 MSM containing $4.0 \mathrm{mg} \mathrm{L}^{-1}$ IBA after 4 weeks of culture

designed to investigate whether the modification of vitamin concentrations positively affects the root formation of $P$. serrulata Kwanzan in vitro. In this experiment, basal media (1/2 MS or $1 / 2$ MSM) were supplemented with 3.0 or $4.0 \mathrm{mg} \mathrm{L}^{-1}$ IBA. The results presented in Table 4 show that the best results were obtained from the $1 / 2$ MSM medium supplemented with $4.0 \mathrm{mg} \mathrm{L}^{-1}$ IBA which produced roots in all the shoots. The mean number and the mean length of roots also significantly improved as compared to the $1 / 2$ MS medium fortified with $4.0 \mathrm{mg} \mathrm{L}^{-1}$ IBA (Table 4).

\section{Acclimatization}

Effects of different mixtures of substrates on acclimatization

The in vitro 6-week-old plantlets were acclimatized during the period of October November when the weather in Hanoi is dry and cool. The data pertaining to the influence of different mixtures of substrates on the survival and growth of plantlets are shown in Table 5 . The survival rate ranged from 46.67 to $66.67 \%$.
The survival rate of in vitro plantlets grown in a mixture of alluvial soil, coco peat, and smoked rice husks $(2: 2: 1, \mathrm{v} / \mathrm{v} / \mathrm{v})$ or in a mixture of alluvial soil and coco peat $(1: 1, \mathrm{v} / \mathrm{v})$ was $66.67 \%$ for both treatments. The mean length of the shoots in the former was $4.27 \mathrm{~cm}$, which was higher than that in the later $(3.55 \mathrm{~cm})$. There was no statistically significant difference in the mean number of leaves between the two treatments. In addition, the use of the mixture of alluvial soil, coco peat, and smoked rice husks $(2: 2: 1, \mathrm{v} / \mathrm{v} / \mathrm{v})$ was more economical than the mixture of alluvial soil and coco peat $(1: 1, \mathrm{v} / \mathrm{v})$. Therefore, the mixture of alluvial soil, coco peat, and smoked rice husks was selected as the suitable mixture for acclimatization. The highest survival rate in this experiment was only $66.67 \%$ probably due to the weather conditions. During the December - January period when the temperature is lower, 150 in vitro plantlets were grown in the selected mixture and the survival rate was $100 \%$. The results indicated that the growth of in vitro plantlets in the acclimatization study was influenced by not only the mixture of 
Table 5. Effects of different mixtures of substrates on survival rate during a 4-week-acclimatization period

\begin{tabular}{lccc}
\hline \multicolumn{1}{c}{ Treatments } & Survival rate $(\%)$ & Mean length of shoots $(\mathrm{cm})$ & Mean no. of leaves \\
\hline $\begin{array}{l}\text { Alluvial soil, coco peat, and smoked } \\
\text { rice husks }(2: 2: 1, \mathrm{v} / \mathrm{v} / \mathrm{v})\end{array}$ & 66.67 & 4.27 & 10.10 \\
Alluvial soil and coco peat $(3: 1, \mathrm{v} / \mathrm{v})$ & 46.67 & 4.31 & 12.00 \\
Alluvial soil and coco peat $(1: 1, \mathrm{v} / \mathrm{v})$ & 66.67 & 3.55 & 9.90 \\
$\mathrm{LSD}_{0.05}$ & & 0.58 & 1.07 \\
$\mathrm{CV} \%$ & & 0.6 & 4.4 \\
\hline
\end{tabular}

substrates but also the weather conditions. Japanese cherry originated from Japan, a temperate country. The weather in December January in Hanoi is similar to spring in Japan which is suitable for Japanese cherry growth.

Effects of in vitro plantlet age on acclimatization and developed the micropropagation protocol

The effect of plantlet age was also examined to investigate whether age affects the survival rate during acclimatization. The plantlets were moved into acclimatization on December 7 and were grown in the mixture of alluvial soil, coco peat, and smoked rice husks $(2: 2: 1, \mathrm{v} / \mathrm{v} / \mathrm{v})$. The results are presented in Table 6. With the optimal mixture of substrates and weather conditions, the survival rate observed for 5-week-old plantlets was $93.33 \%$, while the survival rate of 6 or 7 -week-old plantlets was $100 \%$. There was no statistically significant difference among treatments in terms of the average height increase of shoots. However, the mean number of new leaves in the older plantlets was significantly higher than that of the younger plantlets. In general, although plantlet age showed minor differences in survival rate, 6 or 7 -week-old plantlets should be used for acclimatization to increase the survival rate as well as the growth rate.

The results obtained suggest that we have developed the practical and efficient protocol of micropropagation of Japanese cherry by using nodal segments. The protocol consists of four major steps as shown in Figure 4, including selection of the initial materials, initial culture, shoot proliferation, rooting and acclimatization. Our current work provides a practical protocol for efficiency of single-nodal-stems of Japanese cherry. As compared with the previous work (Harada and Murai, 1996), we successfully developed the in vitro multiplication protocol with approximately 20 weeks of time span.

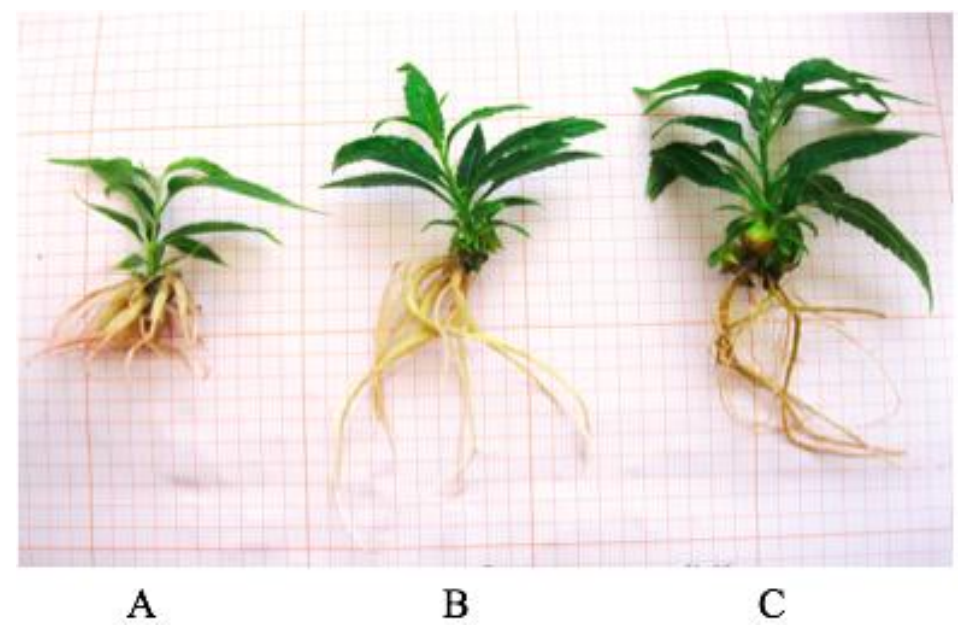

Note: A. 5-week-old; B. 6-week-old; C. 7-week-old.

Figure 3. Plantlets at different stages used for acclimatization 
A practical and efficient method for the micropropagation of japanese cherry (Prunus sp.)

Table 6. Effects of plantlet age on survival rate during a 4-week-acclimatization period

\begin{tabular}{lccc}
\hline \multicolumn{1}{c}{ Plantlet age } & Survival rate $(\%)$ & Average height growth $(\mathrm{cm})$ & Mean no. of new leaves \\
\hline 5-week-old & 93.33 & 1.06 & 1.36 \\
6-week-old & 100 & 1.15 & 2.84 \\
7-week-old & 100 & 1.07 & 3.99 \\
LSD $_{0.05}$ & & 0.36 & 0.58 \\
CV\% & & 1.4 & 0.9 \\
\hline
\end{tabular}

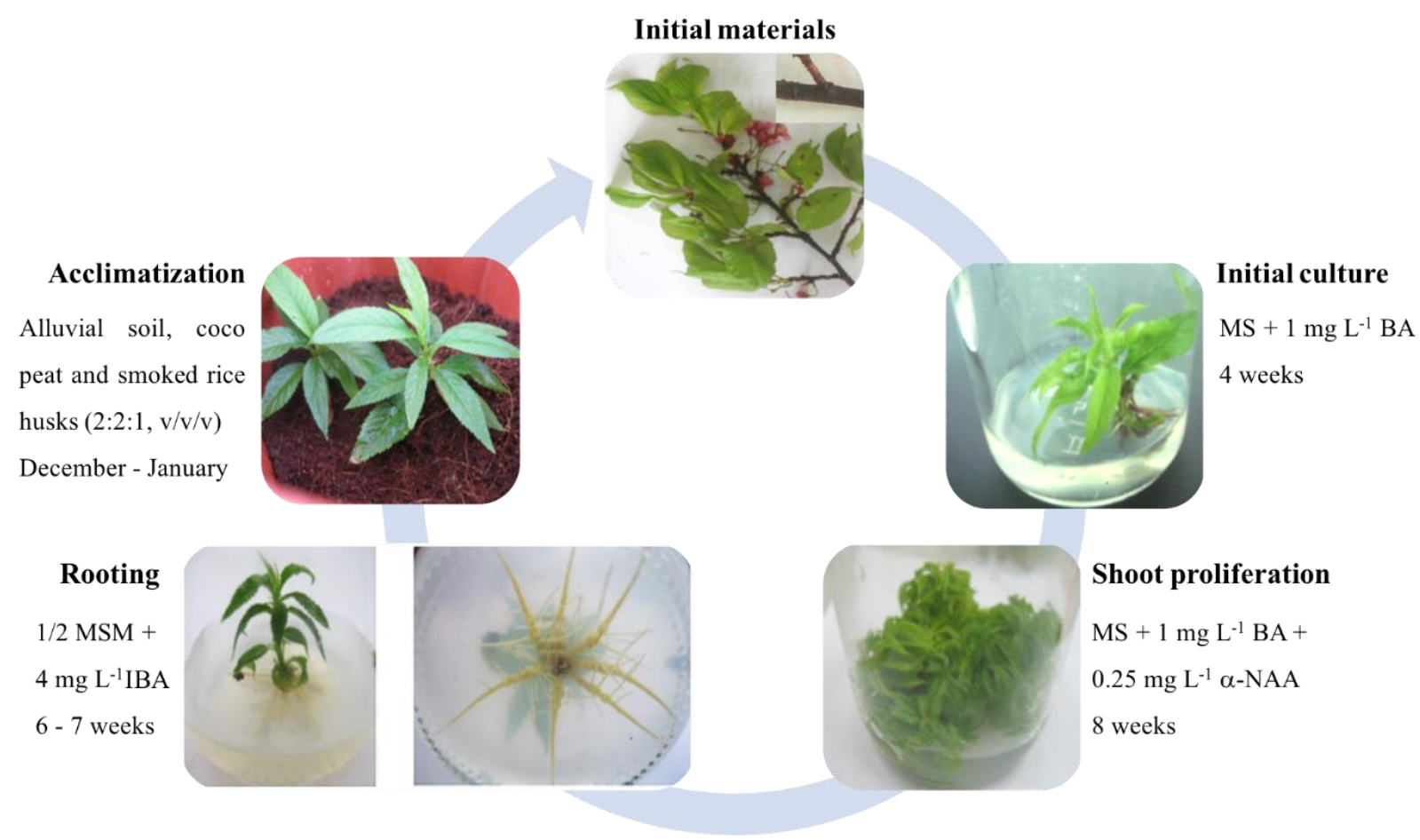

Figure 4. Micropropagation cycle of Japanese cherry

\section{Conclusions}

The micropropagation cycle of Japanese cherry based on vegetative proliferation included the establishment of tissue culture via introduction of nodal stems in vitro, shoot multiplication, rooting, and plant acclimatization steps with the optimal composition of culture media and culture conditions determined for all the stages. The shoot multiplication rate was highest on MS medium supplemented with $1 \mathrm{mg} \mathrm{L}^{-1} \mathrm{BA}$ and $0.25 \mathrm{mg} \mathrm{L}^{-1}$ $\alpha$-NAA after 8 weeks of culture. The best medium for rooting was $1 / 2 \mathrm{MSM}$ medium containing $4 \mathrm{mg}$ $\mathrm{L}^{-1}$ IBA, with a rooting rate of $100 \%$ and a mean of 10.10 roots per plant within 4 weeks. At the acclimatization stage, a high survival rate (100\%) and high-quality plantlets were obtained when growing the rooted plantlets in a soil:coco peat:smoked rice husks $(2: 2: 1, \mathrm{v} / \mathrm{v} / \mathrm{v})$ substrate during the period from December to January. The entire procedure starting from shoot initiation to plant establishment under greenhouse conditions required approximately 5 months. The established micropropagation protocol of Japanese cherry (Prunus sp.) would provide simple and efficient tools for continuous production of plantlets and initial planting materials for further studies, such as using genetic transformation to produce a Japanese cherry variety adapted to Hanoi weather.

\section{Acknowledgements}

This work was funded by Vietnam National University of Agriculture under grant T201212-45. 


\section{Refferences}

Anh N. T. L., Thanh H. T. T., Phuong N. T. T. and Hung N. T. (2009). Study on in vitro culture of Nhat Tan peach. Journal of Science and Development. Vol 7 (4). pp. 387-393 (in Vietnamese).

Amzallag G. N., Lerner H. R. and Poljakoff-Mayber A. (1992). Interaction between mineral nutrients, cytokinin and gibberellic acid during growth of sorghum at high $\mathrm{NaCl}$ salinity. Journal of Experimental Botany. Vol 43 (246). pp. 81-87.

Choudhary R., Chaudhury R., Malik S. K. and Sharma K. C. (2015). An efficient regeneration and rapid micropropagation protocol for almond using dormant axillary buds as explants. Indian Journal of Experimental Biology. Vol 53 (7). pp. 462-467.

Ďurkovič J. (2006). Rapid micropropagation of mature wild cherry. Biologia Plantarum. Vol 50 (4). pp. 733736.

Duta M. (2008). Research concerning the behavior of the Prunus serrulata "Kwanzan" variety in the process of in vitro reproduction. Bulletin UASVM, Horticulture. Vol 65. pp. 84-89.

Faisal M., Ahmad N., Anis M., Alatar A. A. and Qahtan A. A. (2018). Auxin-cytokinin synergism in vitro for producing genetically stable plants of Ruta graveolens using shoot tip meristems. Saudi Journal of Biological Sciences. Vol 25 (2). pp. 273-277.

Fatima N., Ahmad N. and Anis M. (2011). Enhanced in vitro regeneration and change in photosynthetic pigments, biomass and proline content in Withania somnifera L. (Dunal) induced by copper and zinc ions. Plant Physiology and Biochemistry. Vol 49 (12). pp. 1465-1471.

Fatima N. and Anis M. (2012). Role of growth regulators on in vitro regeneration and histological analysis in Indian ginseng (Withania somnifera L.) Dunal. Physiology and molecular biology of plants: an international journal of functional plant biology. Vol 18 (1). pp. 59-67.

Fotopoulos S. and Sotiropoulos T. E. (2005). In vitro rooting of PR 204/84 rootstock (Prunus persica $\times$ P. amygdalus) as influenced by mineral concentration of the culture medium and exposure to darkness for a period. Agronomy Research. Vol 3 (1). pp. 3-8.

Harada H. and Murai Y. (1996). Micropropagation of
Prunus mume. Plant Cell, Tissue and Organ Culture. Vol 46. pp.105-119.

Hartman H. T., Kester D. E., Davies F. T. and Geneve R. L. (2010). Hartmann and Kester's Plant Propagation: Principles and Practices. NJ, USA, Prentice Hall.

Hasan S. Z. U., Ahmad T., Hafiz I. A. and Hussain A. (2010). Direct plant regeneration from leaves of Prunus rootstock GF-677 (Prunus amygdalus $x P$. persica). Pakistan Journal of Botany. Vol 42 (6). pp. 3817-3830.

Hrusa F., Ertter B., Sanders A., Leppig G. and Dean E. (2002). Catalogue of non-native vascular plants occurring spontaneously in California beyond those addressed in The Jepson manual Part I. Madrono. Vol 49 (2). pp. 61-98.

Kalinina A. and Brown D. C. W. (2007). Micropropagation of ornamental Prunus spp. and GF305 peach, a Prunus viral indicator. Plant Cell Reports. Vol 26 (7). pp. 927-935.

Mahdavian M., Bouzari N. and Abdollahi H. (2011). Effects of media and plant growth regulators on micropropagation of a dwarfing cherry rootstock (PHL-A). Biharean Biologist. Vol 5 (2). pp. 86-90.

Mansseri-Lamrioui A., Louerguioui A., Bonaly J., Yakoub-Bougdal S., Allili N. and Gana-Kebbouche S. (2011). Proliferation and rooting of wild cherry: The influence of cytokinin and auxin types and their concentration. African Journal of Biotechnology. Vol 10 (43). pp. 8613-8624

Murashige T. and Skoog F. (1962). A revised medium for rapid growth and bio assays with tobacco tissue cultures. Physiologia Plantarum. Vol 15 (3). pp. 473497.

Tančeva C. O. and Kajba D. (2016). Micropropagation of wild cherry (Prunus avium L.) from a clonal seed orchard. Šumarski list. Vol 140 (5-6). pp. 273-281.

Yildirim H., Onay A., Tilkat E. and Akturk Z. (2011). Micropropagation of the apricot (Prunus armeniaca L.) cv. Hacihaliloğlu by means of single node culture. Turkish Journal of Agriculture and Forestry. Vol 35. pp. 55-64.

Zou Y. N. (2010). Micropropagation of Chinese plum (Prunus salicina Lindl.) using mature stem segments. Notulae Botanicae Horti Agrobotanici Cluj-Napoca. Vol 38 (3). pp. 214-218. 